\title{
The history of novel dermatology and dermatopathology in different countries - Italy
}

\author{
Nooshin Bagherani ${ }^{1 *}$, Bruce R Smoller ${ }^{2}$ and Torello Lotti ${ }^{3}$ \\ ${ }^{1}$ Dermatologist at Dr. Nooshin Bagheran's office, Taha Physicians' building, P.O. Box: 6414715878, Khoramshahr, Khuzestan Province, Iran \\ ${ }^{2}$ Professor and Chair, Department of Pathology, Professor, Department of Dermatology, University of Rochester, School of Medicine and Dentistry, USA \\ ${ }^{3}$ Professor \& Chair of Dermatology, University of Rome “G.Marconi”, Rome, Italy
}

\section{Introduction}

Italy, officially the Republic of Italy (Italian: Repubblica italiana), is located in Southern Europe, between latitudes $35^{\circ}$ and $47^{\circ} \mathrm{N}$, and longitudes $6^{\circ}$ and $19^{\circ}$ E. It covers an area of $301,338 \mathrm{~km}^{2}(116,347 \mathrm{sq} \mathrm{mi})$ and has a Mediterranean climate. Italy has 61 million inhabitants and is a highly developed country. This boot- shaped country has the third largest economy in the Eurozone and the eighth-largest in the world. Because of a very high human development index, Italy has the highest life expectancy in the European Union.

\section{An overview on the history of dermatology in Italy}

\section{The Renaissance period (The fifteenth and sixteenth centuries)}

At the beginning of the sixteenth century, Italian dermatology was dominated by the enormous interest aroused by the epidemic of the "French disease", also known as the "new disease", "Neapolitan disease", and "Great Pox", in association with the invasion by Charles VIII [1]. Later, this disease was named "syphilis'. In these years, large numbers of authors were attracted by this new disease. Girolamo Fracastoro (1478-1553) (Figure 1) was one of these authors. "Syphilis, sive morbus gallicus" and "De contagione etcontagiosis" are among his most important works; the term" syphilis" has been derived from the first work, and the second one is a precursor of modern bacteriology. He introduced mercury for the treatment of syphilis.

From this century, we can also mention Gabriele Falloppio (15231562) who wrote the "Libelli duo, alter de ulceribus, alter de tumoribus

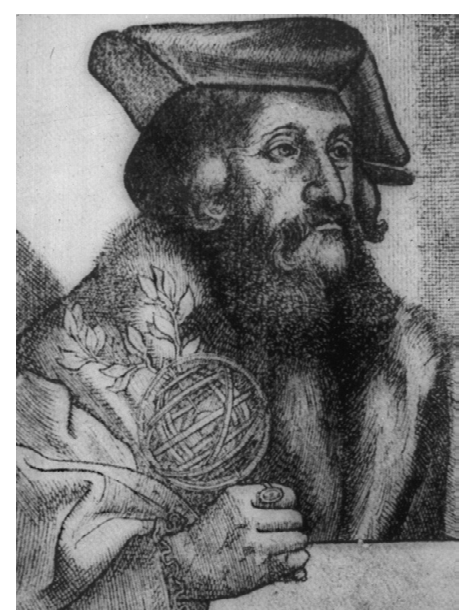

Figure 1. Girolamo Fracastoro (1478-1553). praeter naturam" in which he has given his own acute and original observations about the behavior of small pieces of skin and grafting. "De morbis cutanei et omnibus corporis humani excretionibus" was the first treatise of skin disease which was written by Gerolamo Mercuriale (1530-1606) and addressed the scalp, hair loss, baldness, alopecia, ophiasis, leucotrichia, pityriasis amiantacea, pediculosis, ringworm and sycosis.

\section{The seventeenth century}

This century was the century of the great anatomists such as Malpighi, Valsalva, and Morgagni, but no great work was done in the dermatology field. Bartolomeo Buonaccorsi (1618-1656) in this century listed dermatoses in "De externis malis opusculum". Additionally, we can mention the role of Giovanni Cosimo Bonomo and Diacinto Cestoni in discovering scabies.

\section{The eighteenth century}

In this century we can recall Bernardino Ramazzini (1633-1714), the author of "De morbis artificum diatribe". In this work, Ramazzini described dermopathies of workers, and their prophylactic and therapeutic methods, the first treatise of its kind in the world literature.

Francesco Frapoli was another figure in this century. He described the so-called "male della rosa", and he was the first to use the term "pellagra".

Florentine Vincenzio Chiarugi (1759-1820) was the first Italian physician who played a great official role in dermatological training after

Correspondence to: Nooshin Bagherani, Dermatologist at Dr. Nooshin Bagheran's office, Taha Physicians' building, P.O. Box: 6414715878, Khoramshahr, Khuzestan Province, Iran, Tel: 00989165828461; E-mail: nooshinbagherani@yahoo.com

Special Issue: Dermatology History in Different Countries

Nooshin Bagherani, M. D.

Dermatologist at Dr. Nooshin Bagheran's office, Taha Physicians' building, P.O.Box: 6414715878, Khoramshahr, Khuzestan Province, Iran; Email: nooshinbagherani@yahoo.com

Bruce R. Smoller, M. D.

Chair, Department of Pathology and Laboratory Medicine Professor, Department of Pathology and Laboratory Medicine Professor, Department of Dermatology University of Rochester School of Medicine and Dentistry, USA E-mail: smollerbrucer@uams.edu

Published: December 20, 2015 
obtaining the chair of "Cutaneous Diseases and Mental Disturbances". He was the author of "Trattato sulle malattie cutanee sordide".

\section{The nineteenth century}

At the end of the eighteenth and the beginning of the nineteenth century, dermatology was practiced by generic physicians and surgeons' and its current discipline was founded. In these years, figures such as Robert Willan (1751-1812) from England, and Louis Alibert (1768-1837) from France played fundamental roles. Wilson, Baker, Rosembach, Hutchinson, and Paget described diseases that are now known by their own names, respectively.

In Italy, this period coincided with the Italian unification (18021805), and subsequently foundation of the Kingdom of Italy. In these years, a number of Italian University Medical Schools were suppressed and the structures underwent significant changes. Subsequently, dermatology was hardly considered as an independent discipline, although certain hospitals including "San Gallicano" in Rome and "Ospedale di Bonifazio" in Florence were already devoted largely or entirely to the treatment of dermatological disorders.

\section{The eleventh century}

Treatises obstetrics, gynaecology, and cosmetology are attributed to Trotula de Ruggiero who lived in this century and was one of the most famous physicians of the School of Salerno. "De Ornatu Mulierum" also known as Trotula Minor is one of her work, which is a great treatise on cosmetics, comprising an array of procedures and preparations.

In those years, The Salerno Medical School which is universally recognized as the first and most important medical institution in mediaeval Europe, grew various aspects of dermatological interests.

\section{History of some of famous dermatology hospitals in Italy}

\section{San Gallicano}

San Gallicano (Figure 2), which was founded in 1725, was the first hospital in Europe specific to the treatment of skin diseases. Although the hospital Saint Louis in France had been founded before San Gallicano in 1607, it became a dermatological hospital much later, in 1801. Most patients suffering from contagious, pruritic, and venereal diseases whom had not been accepted by other hospitals were referred

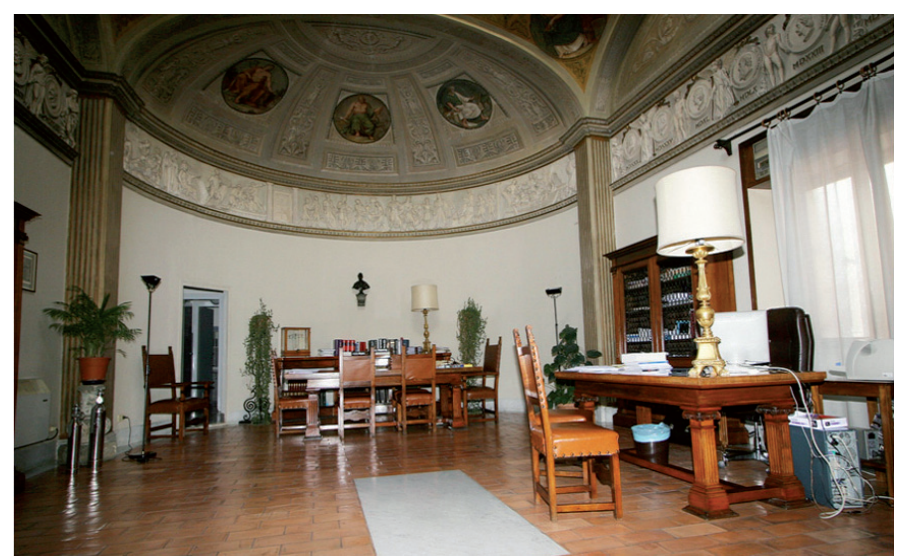

Figure 2. San Gallicano Hospital. to this hospital. At beginning, there were more nursing staff than physicians.

San Gallicano was composed of men's and women's wards and a clinic for dealing with the medication of the poor patients suffering from contagious disorders especially scabies. At that time, three types of "pruriginosis" were identified including simple, feverish, and scabies. The term "scabies" was referred to a number of diseases. For example, scabies located on the head can probably be meant ringworm. The term "rognosi febbricitanti" was defined as extensive dermatoses, probably contagious and pruriginous, in association with more serious general conditions. It appears that this group of dermatoses included all the primary or secondary erythrodermic or sub-erythrodermic eruptions affecting large areas of the integument such as psoriasis, eczema, lymphomas, Norwegian scabies etc.

Between 1860 and 1867, San Gallicano was managed by Casimiro Manassei, who was the first Chair of dermatology in Rome andthe Società Italiana di Dermatologia e Sifilografia. During these years, San Gallicano opened up to the national and international scientific community, and became an authentic clinical and scientific dermatological hospital.

After Manassei, the chair of San Gallicano was given to Schilling (1867-1893). During his tenure, the first syphilis cases were accepted to the hospital. In this period, Maiocchi started his cooperation with San Gallicanoas an intern assistant, after which he was awarded the Chair of Dermatology at Parma, and Bologna. Later, Ciarrocchi (18931925) directed venereal pathology within the dermatological ambit, and began to treat patients suffering from gonorrhoea.

At the end of the nineteenth century, "Sale Celtiche" was set up as the official health control of venereal disease, and began to treat women suffering from syphilis and gonorrhoea in the contagious phase. Between 1937 and 1944, the average number of admissions to the Sale Celtiche was 650 a year, as recorded by Meineri (1934-1953). At the end of the First World War, the Sale Celtiche faced a great increase in this statistics, so that in one year between 1944-45 3,000 patients were admitted. In addition to recording statistics, Meineri noticed to the social problem of prostitution as a source of the disease spread.

Later, San Gallicano was equipped with radiation and phototherapy devices. In 1932, the hospital was transformed into a Hospital Institution of a Scientific Character, equipped with a complete library.

After the 1990s, transformation of San Gallicano into a modern dermatology institute was completed by the foundation of the experimental laboratories specialized to cutaneous physiopathology, dermatopathology, biochemistry, porphyrias, microbiology, new diagnostic techniques such as electronic microscopy, telethermography, and new clinics such as allergology, paediatrics, oncology, and plastic surgery.

\section{Orbatello}

The history of Orbatello refers to 1372, when Nicolò degli Alberti built a great poorhouse for destitute, elderly women. Secondary to a sequence of events around the year 1700, it became a hospital. In that time, under the effect of the belief in Florence that unmarried women can interrupt a pregnancy, a campaign to legalize abortion was made. This fact aroused the wrath of Pope Innocent XI. Then, Father Filippo Franci supported unmarried pregnant women until they gave birth in his assigned role in the Orbatello.

In 1836, a great change took place under the direction of Vincenzo 
Chiarugi, who had been professor of "Skin Diseases and Intellectual Disorders" at the Hospital of San Giovanni Battista or Bonifazio since 1802. Hence, the poor old women began to be sent away, and the hospital was specialized to the treatment of skin disorders.

During a cholera epidemic, Nicolò Bruni-Chiarugi's second successor in the direction of the Orbatello moved the skin patients to the Hospital of Santa Lucia di Camporeggi.

In 1869, under the Regulation of the Ministry of the Interior on prostitution, the new syphilitics' ward was set up in the Orbatello. Hence, the last old ladies were relocated and all the skin patients left at Santa Lucia di Camporeggi were finally transferred to the Orbatello in 1888. From that day on, Orbatello became the location of the Dermosyphilopathic Clinic of Florence, directed, by Celso Pellizzariat the end of the century.

Celso Pellizzari (Figure 3) noticed phototherapy, especially using "actinic" orultra-violet rays, for the treatment of lupus vulgaris and gave a lecture about it in the "Florentine Committee of the Anti-Tuberculosis League". From this observation, the idea of creating an Institute for Phototherapy in Florence resembling the one in Copenhagen adopted by Niel Finsen arose. In January 1904, the idea took shape as the first public phototherapy center in Italy. By the end of 1904, less than a year after the idea was born, this center was fully equipped and functional. Afterward, other physical therapies including Roentgen dermatological therapy, photochromotherapy, electrotherapy, high frequencies and Marconi therapy were gradually added into the Orbatello.

In 1904, Pellizzari also acquired information about the treatment of skin tumor using radium applications. One year later, he purchased ten milligrams of radium from London, and took it in a small ebonite box personally to Florence. In 1907, the Florentine Institute of Phototherapy was the first in Italy which used radium systematically for treatment of skin malignancies.

Pellizzari died in 1925. After him, Jader Cappelli and his assistant, Mario Scopesi, a brilliant master of radiotherapy for the new generation, managed the Institute of Radiotherapy. After Cappelli, in 1949 Enea G Scolari was named director of this institute. Gradually, radiation protection measures and Roentgen therapy equipment were updated and plastic and reconstruction surgery services were established. During this period, the original technique of hyperbaric oxygen radiotherapy was discovered, which drew the attention of radiotherapists from the USA. In 1966, the ground floor of the institute was devastated by the

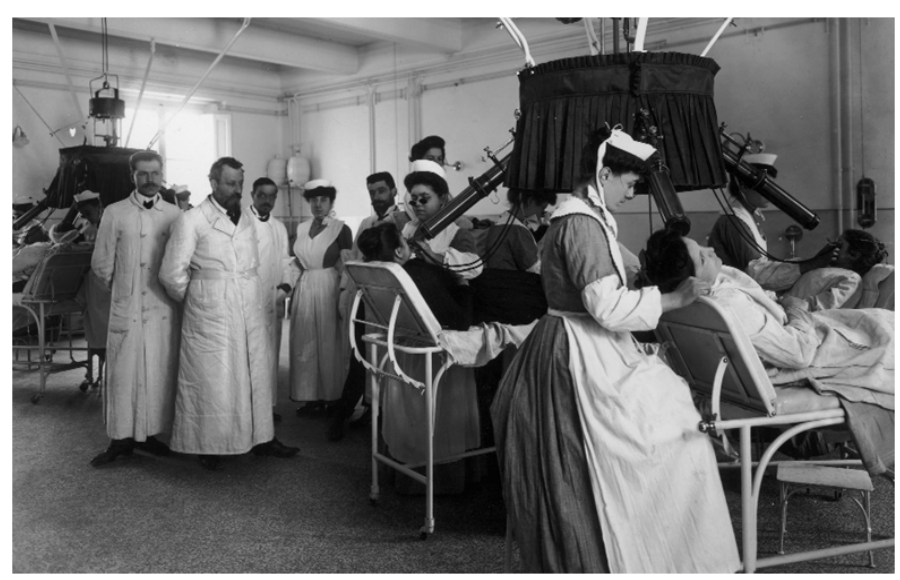

Figure 3. Pellizzari and his staff at the Institute Fotoradioterapico of Florence. flood of the Arnoriver and unfortunately, thousands of precious slides of clinical cases were lost.

After Scolari's death, Emiliano Panconesi took up the heritage of Chiarugi and Pellizzari; owing to his efforts, the Faculty of Medicine and Surgery of Florence, in 1982, was the first in Italy in introducing dermatological physiotherapy.

In 23 november 2005, Prof. Torello Lotti, the chairman of the University Unit of Dermatological Physiotherapy in Florence, commemorated the first hundred years of the activity of "Fotoradioterapico" Institute/Dermatological Physiotherapy Unit.

\section{The most famous Italian figures playing important roles in novel dermatology and dermatopatholgy}

After the Italian unification in the years 1859-1861, the teaching of syphilography, and dermatology was begun almost simultaneously in the most important Italian universities, hospitals, and specialized clinics such as Ospedale San Gallicano in Rome, Ospedale Gesù e Maria in Naples, Ospedale Maggiore in Milan, and the Istituto Superiore di Studi Pratici e di Perfezionamento in Florence. Regarding the Casati law, "Clinica Dermosifilopatica" was established as one of the 24 mandatory teaching subjects. This law was enacted on 13 September 1862. Before this date, syphilography was subsumed within surgery whereas the dermatology was delegated to internal medicine. Among the most important figures who started the teaching of dermatology and venereology during those years, we can recall Casimiro Manasseiat the San Gallicano hospital in Rome, Augusto Michelacci in Florence, Pietro Gamberini in Bologna, and Angelo Scarenzioin Pavia.

Two great events in the history of Italian dermatology include: A: The foundation of the Italian Journal of Venereal and Skin Diseases which was started by GB Soresina in Milan in 1866, and B: The foundation of the Society of Dermatology and Syphilography in Perugia in 1885.The Italian Society held two important International Congresses of Dermatology, one in 1912 in Rome (De Amicis as chairman,Ciarrocchi as secretary) and in 1972 in Padua-Venice (Flarer as chairman, Serri as secretary).

At the end of the $19^{\text {th }}$ century and the start of the $20^{\text {th }}$ century two invaluable figures played a great role in developing Italian dermatology; Celso Pellizzari who taught dermatology and syphilography in Florence from 1892 to 1925, and Tommaso De Amicis who taught in Naples from 1880 to 1914. This novel dermatology was further buit upon by Francesco Radaeli, Vittorio Mibelli, Amedeo Marianelli, Umberto Mantegazza, Agostino Mibelli and Jader Cappelli who were Pellizzari's pupils, and Augusto Ducrey, Rodolfo Stanziale, Giuseppe Verrotti and Lodovico Tommasi who were De Amicis's pupils.

\section{Vincenzio Chiarugi}

Vincenzio Chiarugi (1759-1820) earned his university degree in Pisa in 1779. Then in 1782, he started his work as assistant at the Hospital of Santa Maria Nuova in Florence and, six months later, as "Infirmarius", that is Head Physician of a male ward; after the addition of the Hospital of Bonifazio to Santa Maria Nuova, he was appointed as "Primus Infirmarius. In that period, diseases were divided into the "incurable", which included venereal illnesses that were called aphrodisiac by Chiarugi (especially syphilis), the "invalids", the "demented" and the "skin diseased".

Chiarugi wrote various invaluable texts, among which "Theoreticalpracticalessay on sordid skin diseases observed at the Royal Hospital of 
Bonifazio in Florence", "Essay of researches on pellagra”, and "Regulation for the examinations of students of medicine, surgery and pharmacy" are the most important.

In 1805 , Chiarugi was appointed as professor at the University of Pisa and lecturer in Florence. This was a good opportunity for him to begin his lessons on "Sordidcutaneous diseases and intellectual perturbation".

\section{Angelo Scarenzio}

In 1861, Angelo Scarenzio (Figure 4) (1831-1904) was the first university professor who occupied the chair of Dermatology and Syphilology in Pavia. He was in this discipline for 43 years up to his death.

Scarenzio's first professional career was in the field of surgery, under the supervision of the great surgeon Porta. Soon he became assistant professor of clinical surgery at the University of Pavia. Later, he moved on to the area of Dermatology and Syphilology. During his academic life as surgeon, he published numerous works on surgical fields. In 1894, the King of Italy, Umberto I, admired him as a successful plastic surgeon at the Hygiene Exhibition of the International Medical Congress in Rome.

Between the fields of dermatology and syphilology, Scarenzio was more interested in the latter. He managed a clinic devoted especially to syphilis. He used his skills as a surgeon for repairing the destructive lesions caused by the later stages of syphilis. At his own expense, he endowed a Dermatology and Syphilology Museum with a number of wax models of dermatological diseases.

Scarenzio was internationally famous in the field of venereology for treating syphilis with subcutaneous injection of calomel, or mercury chloride. His experience in this arena was published as article entitled "First attempts at the treatment of constitutional syphilis via subcutaneous injection of a preparation of mercury" in the AugustSeptember 1864 issue of the Annali Universali di Medicina. Although the prize of the gold medal was awarded to Scarenzio and his colleague Ricordi by the Royal Society of Medical and Natural Sciences of Brussels, they failed to disseminate this therapeutic strategy at an international level. Later, Smirnoff in Finland, Balzer and Jullien in France and Neisser in Germany successfully administered modified formulations of Scarnzio's method in treating patients with syphilis.

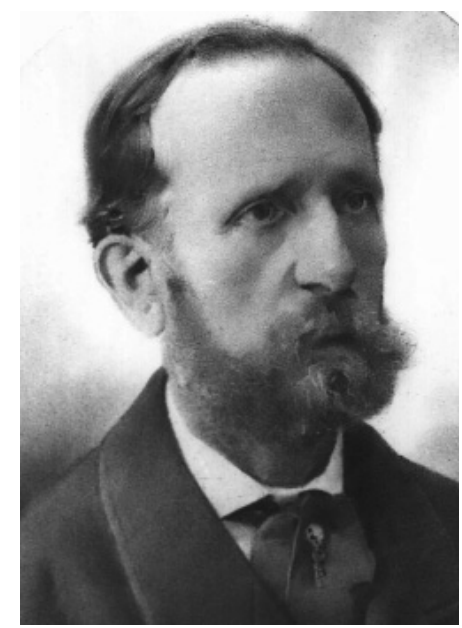

Figure 4. Angelo Scarenzio.

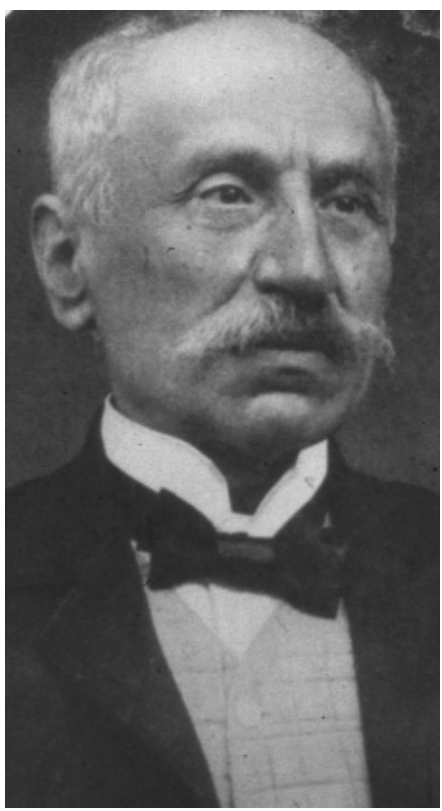

Figure 5. Domenico Barduzzi.

\section{Domenico Barduzzi}

Domenico Barduzzi (1847-1929) (Figure 5) graduated from the University of Pisa in 1872 and obtained the qualification for practicing medicine at the Florence Istituto Superiore in 1876. During his work in this institute, he started learning dermatology under the supervision of Augusto Michelacci.

In1882 Barduzzi obtained the qualification for teaching Clinical Dermatology and Venereology at the University of Modena. Four years later, in 1886 he became the professor of dermatology at the University of Siena. In 1885 , he was the secretary of the promotional committee of the Italian Dermatology Society, and between 1909 and 1911 he became President of this society.

One of his proudest accomplishments was his seeing two of his pupils who reached the height oftheir university career: Vittorio Mibelli and Pio Colombini.

\section{Domenico Maiocchi}

Domenico Maiocchi (1849-1929) graduated in Medicine at the University of Rome in 1973. He worked on various forms of tertiary syphilis. He was professor of Clinical Dermatology and Syphilology at the University of Parma for 11 years. In that period, he described granuloma trichophyticum that after his death was named Maiocchi granuloma. In 1885, Maiocchi took part in the foundation of the Italian Society of Dermatology and Syphilology. In 1896 he introduced purpuraannularis telangiectodes.

\section{Celso Pellizzari}

Celso Pellizzari (1851-1925) graduated in Florence in 1876. He was nephew of Pietro Pellizzari. He was the professor in charge of Dermatology and Syphilology in Siena in 1883. Then from 1884 to 1892 , he was professor at the University of Pisa. He described colloid pseudomilium and Pellizzari's anetoderma. Additionally, he studied several aspects of syphilis (syphilis of thenervous system, syphilis of the placenta), rhinoscleroma and leprosy. For the first time in Italy, he introduced the administration of vioform in dermatology. In 1905, 
he founded a center-"Fotoradioterapico" Institute-for the treatment of skin diseases with ultraviolet rays and $\mathrm{x}$-rays in Florence.

\section{Vittorio Mibelli}

Vittorio Mibelli (1860-1910) (Figure 6) graduated from Siena in 1881. In 1890, he was professor of the Dermatology Department of the University of Cagliari. Mibelli described two cutaneous conditions including an angiokeratoma and a porokeratosis which are nominated after his death.

\section{Umberto Mantegazza}

Umberto Mantegazza (1863-1948) graduated from Pavia. From 1898 to 1905, he was professor of Cagliari and from 1905 to 1935, he was professor of Pavia. He worked extensively on the histopathology of psoriasis and described the intraepidermic collection of neutrophils (the microabscesses of Munro-Mantegazza-Sabouraud).

\section{Pio Colombini}

Pio Colombini (1865-1935) was pupil of Barduzzi in Siena. During 1898 to 1905 , he was professor of clinical dermatology and syphilology in Sassari. There, he founded the Department of Dermatology at the start of the $20^{\text {th }}$ century. In 1907, he discovered the association between gonorrhea and gonococcal arthritis. From 1916 to 1932, he was rector of the University of Modena.

\section{Francesco Radaeli}

Francesco Radaeli (1870-1936) graduated from Pavia in 1895. He collaborated with "Fotoradioterapico" Institute which had been founded by Celso Pellizzari in Florence. He wrote the Textbook of Dermatology before the arrival of the Monacelli-Nazzaro Textbook. In Genoa, Radaeli organized the Dermatology Department and subsequently a new ward for treating patients with leprosy.

\section{Mario Truffi}

Mario Truffi (1872-1963) was the favorite student of Scarenzio, one of the major exponents of Italian dermatology in the twentieth century. He graduated from the University of Pavia. During his courses as intern, he attended Golgi's General Pathology laboratory and Orsi's medical clinic. During the course of clinical dermatology and syphilology, he

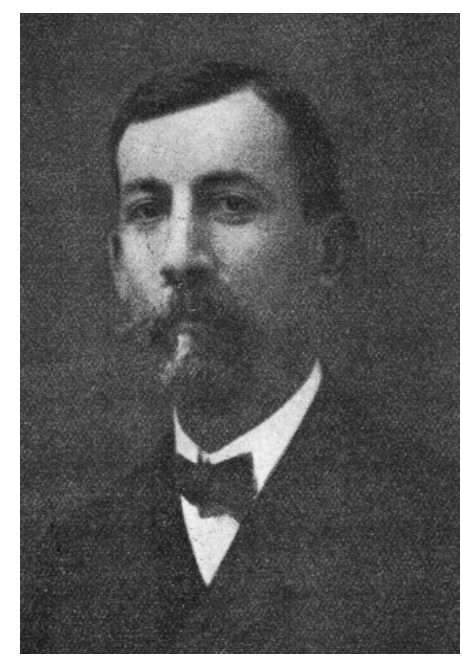

Figure 6. Vittorio Mibelli. attracted the attention and approval of Scarenzio, and after graduation, he worked as Scarenzio's assistant in the clinic.

Truffi completed his clinical and scientific study under training of Professor Monti. He also was in contact with the leading lights of Italian dermatology, particularly Majocchi and Mibelli. In 1901, Truffi successfully passed his examination for qualification as a university teacher when he was 29 years of old. In 1904, the management of hospital and university of Pavia was entrusted to him.

He became famous for his studies on experimental syphilis in rabbits, and his contributions to the progress of anti-luetic treatment. His findings were published in German journals and induced a stir in international scientific world. He succeeded to discover a strain of Treponema pallidum, which was highly virulent for the rabbits and named it "Truffi strain". This strain was the first laboratory strain in the world to be isolated and beside other famous strains such as Nichols, Mulzer and Kuznitsky became widely diffused in international research centers. His discoveries helped Paul Ehrlich and Sahachiro Hata in Frankfurt to introduce of "salvarsan" for treating syphilis, and Levaditi to do the pharmacological experimentation of bismuth for managing syphilis. Truffi was the first physician in Italy who experienced salvarsan and bismuth for the treatment of human syphilis.

During his academic life, Truffi experienced many careers and positions including the position of Chief Physician in Savona for 13 years, the management of the Dermatology and Syphilology Clinic of Messina, as lecturer and professor in Catania, direction of the Clinics of Siena and Padua.

\section{Silvio Ossola}

Silvio Ossola was a brilliant researcher at the Dermatology and Syphilology Clinic of Pavia. He became famous due to his studies on experimental syphilis in rabbits. He succeeded to inoculate syphilis into the testicle of rabbits. His work in this field was in parallel and in completion with the works done by Truffi.

\section{Agostino Pasini}

Agostino Pasini (1875-1944) graduated from Pavia in 1900. From 1922 to 1944, he was professor in Milan. He introduced the atrophoderma of Pasini-Pierini which is progressive disease characterized by bluish or greyish indented lesions.

\section{Ambrogio Bertarelli}

Ambrogio Bertarelli was from a wealthy Milanese family, graduated in Medical Surgery in Milan. He began his professional work in the Municipal Celtic Dispensary of Milan under the supervision of Soresina. Later, he became director of the State Venereal Disease Hospital (Sifilicomio), and in 1885 worked as Chief Physician in the Dermatology and Syphilology department of the Ospedale Maggiore of Milan.

Bertarelli was famous for successful presence at national and international conferences and taking part in discussions. In his academic life, editing the journal of "Giornale Italiano delle Malattie veneree e della pellethe" was considered as his greatest accomplishment. This journal is the oldest journal in the world in the field of dermatology and venereology.

At his expense, Bertarelli funded the enlargement and transformation of the hospital structures into a University Department. Thanks to his efforts, the University of Milan was set up in 1923. 


\section{Cosimo Lombardo}

Cosimo Lombardo (1875-1945) graduated in Turin in 1900. During his academic life, he worked on syphilis, and ringworm. From 1919-1923, he was professor of clinical dermatology at the University of Sassari. During this period, Lombardo founded a physiotherapy center for the treatment of ringworm which at that time was endemic in Sardinia.

\section{Aldo Castellani}

Aldo Castellani (1874-) was the pupil of Celso Pellizzari. He was an internationally known microbiologist. He was interested in dermatology. For the first time, Castellani could centrifuge cerebrospinal fluid and examine for trypanosomes and introduced it as the causative agent for "sleeping response". In addition, in 1905 he discovered Treponema Pertenue, the causative organism of yaws, and introduced arsenobenzoles as the suitable treatment for this disease. "Tinctura antimycotica rubra" or "Castellani Tinctura" which is commonly used in dermatology clinics was introduced by Castellani.

Castellani had an important role in foundation of the "International Society of Tropical Dermatology" which then became the "International Society of Dermatology".

\section{Agostino Crosti}

Agostino Crosti (1896-1988) graduated from Milan University and was trained at the Pasini school. Between 1930-1939, he was professor of Clinical Dermatology and Syphilology at the University of Perugia. In 1945, he took the place of Pasini at the University of Milan and remained there until 1966.

In 1951, Crosti introduced reticulohistiocytoma of the back named Crosti syndrome. In 1957, he along with Gianotti described papular acrodermatitis of childhood or Gianotti-Crosti syndrome.

\section{Umberto Mantegazza}

Umberto Mantegazza graduated at the University of Pavia and passed his specialist training in the Florentine school under the supervision of Celso Pellizzari. After relocating to Pavia, he founded his own school from which many of his graduated students such as Mariani, Falchi, Flarer, Casazza, Baccaredda Boy, and Cottini occupied the chair.

\section{Francesco Flarer}

Francesco Flarer (1899-) was the pupil of Mantegazza in Pavia. From 1930 to 1934, he was director of the Messina Department of Dermatology. From 1957 to 1972, Flarer was a member of the International Committee of Dermatology. His studies on hematologic alterations in the course of cutaneous lupus erythematosus are invaluable.

\section{Ruggero Caputo}

Ruggero Caputo (-2007) (Figure 7) after leaving the Engineering Faculty, went to start medicine. He noticed he was interested in dermatology so that when he was still a student began regularly to visit the Dermatological Clinic in Via Pace in Milano. During this period, he became familial with invaluable figures such as Agostino Crosti, Vittorio Puccinelli, and especially Ferdinando Gianotti, with whom he established a profound friendship.

In 1980, Caputo became Full Professor of Dermatology and fouryears later begun teaching at the First Dermatological Clinic of the University

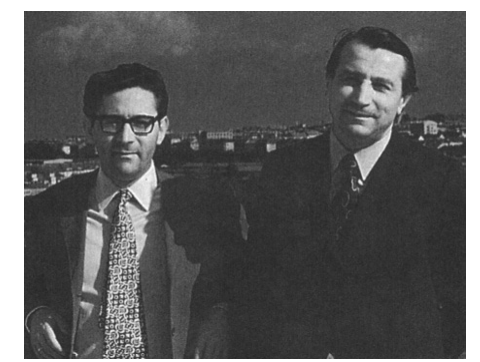

Figure 7. Ruggero Caputo and Ferdinando Gianotti.

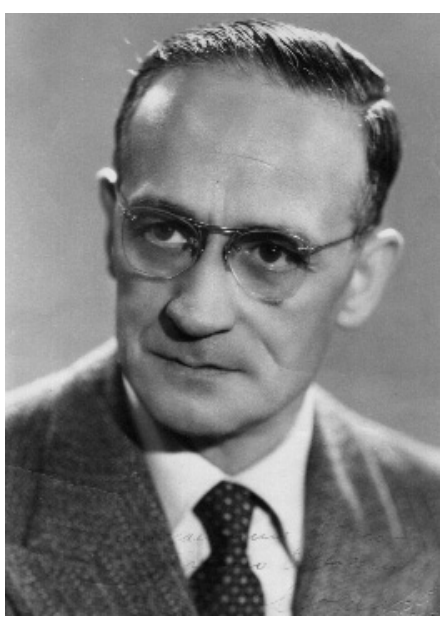

Figure 8. Enea Giuseppe Scolari.

of Milan, a chair he held until he died. He was a great researcher in the field of electronic microscopy and skin immunopathology. He wrote an invaluable four volume work on pediatric dermatology (Pediatric Dermatology and Dermatopathology). He also was a member of the editorial board of the most important international scientific journals of dermatology and for 15 years, was a member of committee of the International League of Dermatological Societies. Among his pupils we can recall Tullio Cainelli, Carlo Crosti, Emilio Berti, Silvano Menni and Carlo Gelmetti.

\section{Enea Giuseppe Scolari}

Enea Giuseppe Scolari (1903-1972) graduated in Pavia. He was the pupil of Collegio Ghislieri from 1921 to 1927. Then, he was the pupil of Pasini until 1939. In 1945, he was a member of the board of experts who carried out the autopsy on Benito Mussolini. In 1950, he organized the 37th National Congress in Florence where he described pyogenic dermatoses (Figure 8).

\section{Antonio Ribuffo}

Antonio Ribuffo (1915-2009) was pupil of Monacelli. From 1965 to 1970 , he was dean of the faculty in Sassari and then from 1970 to 1985, he was in Rome. His main study was on the association between dermatology and internal medicine-"the skin as a window into the body'.

\section{Ferdinando Serri}

Ferdinando Serri (1916-1995) (Figure 9) graduated from Pavia in 1941. In 1969-1970, he participated in organization of the European Society for Dermatological Research (ESDR) where he was the first 


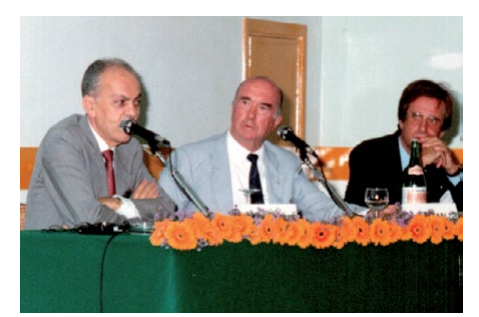

Figure 9. Ferdinando Serri with Decio Cerimele and Giuseppe Fabrizi.

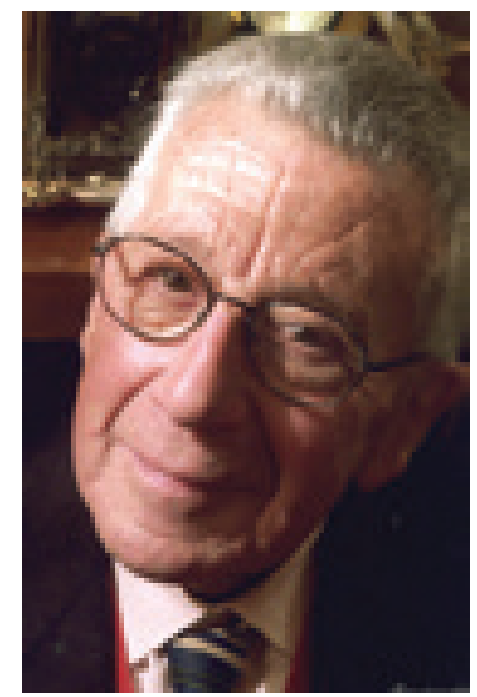

Figure 10. Emiliano Panconesi.

president. From 1967 to 1982, Serri was a member of the International Committee of Dermatology.

Serri participated in studies on embryology of the skin in association with William Montagna that resulted in the publication of a series of significant works in this field.

\section{Emiliano Panconesi}

Emiliano Panconesi (1923- 2014) (Figure 10) was born in Pistoia. He received the medical degree and Specialty in Dermatology and Venereology at the University of Florence, magna cum laude in 1947 and 1949, respectively. He started his work as Assistant Professor at the Department of Dermatology of the University of Florence. Later, he was appointed as Professor and Chair of the 2nd Department of Dermatology and the 1st Department of Dermatology of the Dermatology Residents' School at the University of Florence.

In the years 1972-1995, Panconesi organized one of the most prestigious Schools of Dermatology in Italy and in Europe, with special interest in clinical dermatology, skin immunopathology and psychosomatic dermatology. From 1995 to 2005, he was the President of the European Society of Dermatology and Psychiatry. In the years 1999-2004, Panconesi served as editor of the Journal of Dermatology \& Psychosomatics.

Panconesi introduced the liaison-consultation for treating patients with cutaneous disorders. He has studies on neuropeptides as privileged bridges between the mind and the body keeping the skin as the primary visible psycho-organ.

Panconesi played a great role in the field of the history of medicine.
In years 1990-1995, he was Professor of History of Medicine at the University of Florence.

In 1987-1989, Panconesi was the President of the Italian Society of Dermatology and in 1989-1999, the Executive Vice President of the International Society of Dermatology and in 1995- 2005, the President of the European Society of Dermatology and Psychiatry. He is the founding president of the European Academy of Dermatology and Venereology (EADV).

\section{Lucio Andreassi}

Lucio Andreassi (1934-2013) (Figure 11) was born in San Demetrio nei Vestini (L'Aquila).This internationally renowned dermatologist graduated in general medicine from the University of Siena in 1958 and in specialty of skin and venereal diseases from the University of Florence in 1962. Andreassi was emeritus professor of dermatology and director of the science section in the Dermatology Department at the University of Siena. He spent his entire academic career at this university.

Andreassi is the author of hundreds of scientific papers, and have publications about Italian history of dermatology. He played a great role in developing important scientific achievements especially in the field of dermatology.

Professor Andreassi has been a pioneer in the field of Skin Bio Banks and in the field of Engineering of the Skin.

$\mathrm{He}$ is recognized as the Noble Father of Digital Dermoscopy internationally and nationally.

Professor Lucio Andreassi and Professor Bernard Rudiger Balda founded the Italian - German Dermatology Association named Symposium Augustanum which greatly improved the scientific research cooperation between Italian and German Dermatology and is presently growing and flourishing.

\section{Torello Lotti}

Torello lotti (Figure 12) is one of the most famous contemporary feature of dermatology in the world, who has played a great role in advances in novel dermatology particularly in the ground of vitiligo (www.torellolotti.it). He is Full Professor of the Dermatology and Venereology at University of Studies Guglielmo Marconi, Rome, Italy. He is President of the World Health Academy, Dermatology since 2013 and director of the Centro Studi per la Ricerca Multidisciplinare Rigenerativa (CSRMR), of the University of Rome "G.Marconi", Rome, Italy, since 2015.

He is Honorary Professor of Dermatology - China Medical University Shenyang (2011), Lecturer at the New York Academy of

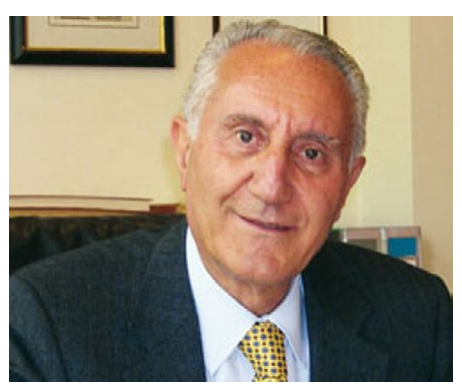

Figure 11. LucioAndreassi. 


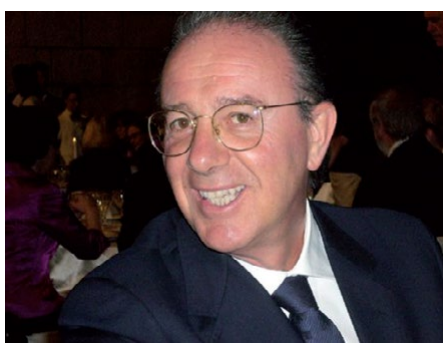

Figure 12. TorelloLotti.

Sciences "Howard Fox Memorial Lecture" (14 March 2012 - New York, NY - USA), and Chair, Executive Scientific Committee Vitiligo Research Foundation, New York, NY USA. He had also been Full Professor of the Dermatology and Venereology Division at University of Florence School of Medicine, Florence, Italy, from 2006 to 2010. He is Visiting Professor in six international universities worldwide, and Key Note Lecturer in several international dermatology societies.

His activities in serving dermatology have been numerous including: President of the Italian Society of Dermatology and Venereology (SIDeMaST , 2009-2010) and President of the International Society of Dermatology ( ISD, 2009-2010), President of the European Society for Cosmetic and Aesthetic Dermatology (2003-2004), Editor in Chief of the Journal of the European Academy of Dermatology and Venereology (1992-2002) , Editor of "Therapeutic Hotline"- Dermatologic Therapy (2007-), Editor in Chief of the "Giornale Italiano di Dermatologia" in the period of presidency of the Societa' Italiana di Dermatologia (20092010), and Editor in Chief of the journal of "Global dermatology".

Lotti has been President of numerous international congresses. $\mathrm{He}$ is Ordinary Member of the main Scientific Societies worldwide (European Academy of Dermatology and Venereology (EADV), Italian Society of Dermatology and Syphilology (SIDES), European Society for Dermatological Research (ESDR), American Academy of Dermatology (AAD), and Scientific Information Database (SID) and Honorary Member of several Scientific Societies of the Dermatology field. He also is Honorary Life Member of American Dermatological Association (ADA).

Furthermore, Lotti is a scientific reviewer of ten sectorial journals, among which are the British Journal of Dermatology, Journal of Investigative Dermatology, Journal of the American Academy of Dermatology and Dermatologic Therapy.

Lotti is author or co-author of over 1500 scientific publications, including scientific papers, book chapters and books. Out of these publications over 500 are peer-reviewed papers, with a cumulative Impact Factor of over 1000.

\section{Societies of Dermatology and Venereology}

\section{Italian Society of Dermatology and Syphilology}

In 1885, Italian Society of Dermatology and Syphilology (SIDES) was founded as a specialized section of the Italian Medical Association. The primary committee was formed by participation of Manassei, Gamberini, Scarenzio, De Amicis, Majocchi, Gibelli, Soresina, Ricordi and Barduzzi which resulted to the foundation of the society contemporary to the $11^{\text {th }}$ Congress of the Italian Medical Association held in Perugia in September 1885. The responsibility of managing this newly founded society given to Professors Manassei and Barduzzi. On 23 April 1886, the first SIDES's assembly of members was held in Rome. At this assembly, the charter of society was approved and the first directors including Casimiro Manassei (chairman), Angelo Scarenzio (vice-chairman), and Domenico Barduzzi (secretary) were chosen.

In 1894, the SIDES separated from the Italian Medical Association and started to work independently under the chairmanship of De Amicis. In subsequent year, the society published its official journal - "Italian Journal of Venereal and Skin Diseases", which later changed its name to the "Italian Journal of Dermatology and Syphilology".

SIDES was inactive during the war in 1915-18. Again, it became active in 1919, when 152 new members were signed in.

\section{International Society of Dermatology}

For the first time in 1912, the foundation of an international society of dermatology that was set up many years later with the "International Society of Dermatology: Tropical, Geographic and Ecologic" was suggested. This was then was replaced by the "International Society of Dermatology" (ISD). Aldo Castellani, along with Frederick Reiss, played an important role in the foundation of this society. Castellani was the Professor of Microbiology and Dermatology lecturer in Ceylon. He was the president of ISD from 1959 to 1964. Since 1964 afterward, Professor Torello Lotti was the only person from Italy who could be president for years 2009 to 2010.

The journal Dermatologia Tropica, which was then renamed "The International Journal of Dermatology" is the professional journal of ISD.

\section{Italian Journals of Dermatology and Venereology}

Among the Italian journals of Dermatology and Venereology, the most important ones include:

Italian Journal of Dermatology and Syphilology

The Italian Archive of Dermatology, Syphilology and Venereology

The Dermosyphilograph

The Italian Annals of Dermatology and Syphilology

The Dermatology Review

The Journal of the S Gallicano Dermatology Institute

Dermatology

The News of the IDI

Italian General Review of Dermatology

Clinical Dermatology

\section{Foundation of a new Chair of Dermatology and Venereology in Italy}

In 2011, Prof Torello Lotti founded a new Chair of Dermatology and Venereology at the University of Rome Guglielmo Marconi. The new Chair rapidly expanded to include an excellent International Faculty of teachers and the Inter Disciplinary Academic Centre for Regenerative Sciences: http://csrmr.unimarconi.it/.

The contribution of the new Dermatology Chair and Department to the development of Italian Research in the international arena has been and is remarkable 


\section{References}

1. https://en.wikipedia.org/wiki
2. Andreassi L, Vallecchi C, Mantellassi G, Cerimele D, Zambruno G, et al. (2010) Italian History of Dermatology, Edizioni Minerva Medica, Saluzzo, Italy.

3. Lotti T, Hercogova J (2014) Emiliano Panconesi; Founding President of EADV; EADV NEWSN $^{\circ} 50$; Spring.

Copyright: $(2015$ Bagherani N. This is an open-access article distributed under the terms of the Creative Commons Attribution License, which permits unrestricted use, distribution, and reproduction in any medium, provided the original author and source are credited. 